\title{
A survey of changing trends in modelling radiation lung injury in mice: bringing out the good, the bad, and the uncertain
}

\author{
Mohamad B Dabjan', Carolyn MS Buck², Isabel L Jackson², Zeljko Vujaskovic ${ }^{2}$, Brian Marples ${ }^{1}$ and Julian D Down ${ }^{3}$
}

Within this millennium there has been resurgence in funding and research dealing with animal models of radiationinduced lung injury to identify and establish predictive biomarkers and effective mitigating agents that are applicable to humans. Most have been performed on mice but there needs to be assurance that the emphasis on such models is not misplaced. We therefore considered it timely to perform a comprehensive appraisal of the literature dealing with radiation lung injury of mice and to critically evaluate the validity and clinical relevance of the research. A total of 357 research papers covering the period of 1970-2015 were extensively reviewed. Whole thorax irradiation (WTI) has become the most common treatment for studying lung injury in mice and distinct trends were seen with regard to the murine strain, radiation dose, intended pathology investigated, length of study, and assays. Recently, the C57BL/6 strain has been increasingly used in the majority of these studies with the notion that they are susceptible to pulmonary fibrosis. Nonetheless, many of these investigations depend on animal survival as the primary end point and neglect the importance of radiation pneumonitis and the anomaly of lethal pleural effusions. A relatively large variation in survival times of C5BL/6 mice is also seen among different institutions pointing to the need for standardization of radiation treatments and environmental conditions. An analysis of mitigating drug treatments is complicated by the fact that the majority of studies are limited to the C57BL/6 strain with a premature termination of the experiments and do not establish whether the treatment actually prevents or simply delays the progression of radiation injury. This survey of the literature has pointed to several improvements that need to be considered in establishing a reliable preclinical murine model of radiation lung injury. The lethality end point should also be used cautiously and with greater emphasis on other assays such as non-invasive lung functional and imaging monitoring in order to quantify specific pulmonary injury that can be better extrapolated to radiation toxicity encountered in our own species.

Laboratory Investigation (2016) 96, 936-949; doi:10.1038/labinvest.2016.76; published online 1 August 2016

Experimental animals have continued to be used to address radiation effects on the lung as the high sensitivity of this tissue remains a concern in humans receiving radiotherapy or unintentional radiation exposures. ${ }^{1,2}$ The purpose of this review is to compile published findings that are pertinent to establishing meaningful animal models for reasonable extrapolation to what might be anticipated in our own species. This covers a comparison of experimental studies spanning four and a half decades, most notably in mice, with respect to the type and timing of pathology and the assays used to measure radiation lung injury. The reliability of these animal models can affect the validity of the various molecular and cellular mechanistic concepts that have been proposed and upon which new therapies can be designed to protect or mitigate radiation pulmonary injury. This review also extends on recommendations from a workshop meeting in 2008 among Centers for Medical Countermeasures against Radiation (CMCRs) that outlined the desire for a consensus on appropriate animal model used to allow for comparative studies to be performed across institutions. ${ }^{3}$ These concerns have been heightened by the need for biomarkers and therapeutics to comply with FDA Animal Rule for approval in humans when it is neither ethical nor feasible to conduct human efficacy studies due to the toxicity of a radiological or

\footnotetext{
${ }^{1}$ Department of Radiation Oncology, William Beaumont Hospital, Royal Oak, MI, USA; ${ }^{2}$ Department of Radiation Oncology, University of Maryland, Baltimore, MD, USA and ${ }^{3}$ Institute for Medical Engineering and Science, Massachusetts Institute of Technology, Cambridge, MA, USA

Correspondence: Dr JD Down, PhD, Institute for Medical Engineering and Science, Massachusetts Institute of Technology, Blg. E25-406,45 Carleton Street, Cambridge, MA 02142, USA.

E-mail: jddown@mit.edu

Received 13 March 2016; revised 10 May 2016; accepted 4 June 2016
} 


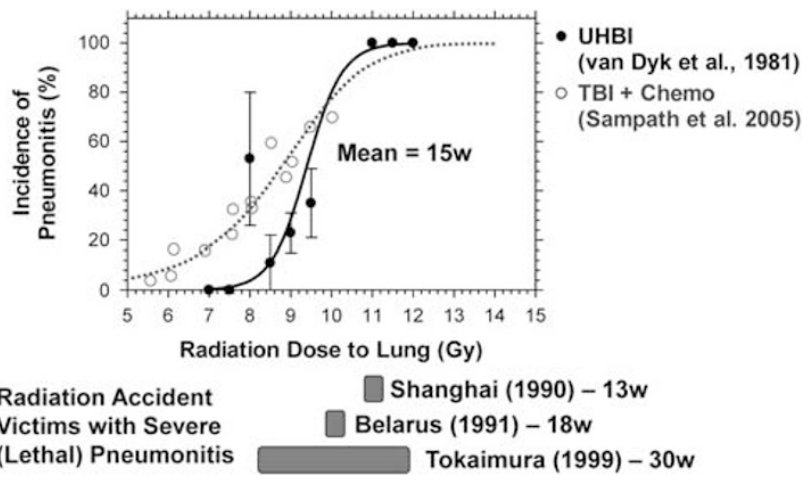

Figure 1 Radiation dose responses for severe pneumonitis among humans receiving either single doses of UHBI $(\bullet)^{8}$ or single dose equivalents of $\mathrm{TBI}(\circ)$, most with cyclophosphamide chemotherapy before allogeneic bone marrow transplantation. ${ }^{15}$ Also compared are the estimated dose ranges for nuclear accident victims that died with latent respiratory failure at Shangai, ${ }^{25}$ Belarus, $^{23}$ and Tokaimura. ${ }^{24}$

nuclear threat to the population. In this case, it is generally understood that the model is sufficiently well characterized to the point that it adequately recapitulates the pathogenesis caused by the threat agent in humans. ${ }^{4}$ Meaningful preclinical animal studies are additionally required to address radiation toxicity to the lung as a side effect of radiotherapy in the treatment of malignant disease and, while less stringent, also requires ultimate regulatory approval for human use in the United States and other countries.

In considering that this review article is focused on murine models of radiation lung injury as representing the majority of experimental animal studies on the topic, comparisons among other animal species have generally been covered elsewhere in terms of anatomical as well as radiobiological differences, ${ }^{3,5}$ but may similarly require greater scrutiny with regard to how the pathological features are a reflection of radiation pulmonary toxicity in patients.

\section{SO WHAT REALLY HAPPENS IN HUMANS THAT SHOULD BE ADDRESSED IN AN ANIMAL MODEL?}

A proper appreciation of the value in a particular animal model obviously requires how it compares with the findings observed in humans. Many papers dealing with the topic of radiation lung damage involving laboratory animals start by making only a casual reference to the clinical findings and where a balanced appraisal is needed as to what is truly encountered following intentional or accidental radiation exposures under analogous conditions. Some offer the general notion that pulmonary fibrosis is the pathology that matters the most. Two main scenarios need to be considered here. The first deals with situations in which all or most of the lung tissue is exposed to radiation, which is often applied to experimental studies in mice. The second addresses localized irradiation in which significant proportions of the lung are excluded from the radiation treatment and maintains sufficient functional reserve for long-term survival regardless of the extent of radiation lung injury within the radiation field. The distinction between radiation exposures to the whole vs regional lung volumes is particularly important in experimental studies that address the relative importance of pneumonitis $v s$ fibrosis.

\section{RADIATION EXPOSURE TO THE WHOLE LUNG}

The clearest impression of radiation effects in humans in which the entire lung tissue is included in the treatment field comes from patients receiving single doses of upper half body irradiation (UHBI) for treatment of disseminated malignant disease at Princess Margaret Hospital, Toronto, Canada ${ }^{6-8}$ and at the University of Rochester Cancer Center, Rochester, NY. ${ }^{9}$ At both centers, the shielding of the gut and much of the bone marrow predictably prevented significant acute toxicities to these tissues but an over-exuberant inflammatory reaction in the lung parenchyma ensued as classical radiation pneumonitis. The high sensitivity of the lung toward radiation pneumonitis was similarly found for fractionated whole thorax in patients treated for pulmonary metastases. ${ }^{10,11}$ The papers by Fryer et $a l^{7}$ and Van Dyk et $a l^{8}$ convey the most important findings following UHBI in that (a) the manifestation of radiation pneumonitis follows an asymptomatic latent period of 2-6 months, (b) the injury rapidly evolves and where $84 \%$ of the patents diagnosed with pneumonitis died from respiratory failure within 2 weeks of its onset, and (c) the incidence is highly dependent on absorbed radiation dose to the lung to produce a steep dose response between 7 and $10 \mathrm{~Gy}$. This curve is shown in Figure 1 that is perhaps the best example of a radiation doseresponse relationship that is close to lethality for any normal tissue in humans. Indeed, the position of this curve is similar to that recently reported for delayed lethality data in rhesus macaques following either localized whole thorax or partial body irradiation (with $\sim 5 \%$ bone marrow shielding). ${ }^{12-14}$ Also presented in Figure 1 is the single-dose equivalent incidence of idiopathic interstitial pneumonitis in patients following total body irradiation (TBI) and bone marrow transplantation. ${ }^{15}$ Although pneumonitis after TBI is certainly more complicated and may be further aggravated by concurrent chemotherapy and graft $v s$ host disease that explains the shift of the curve to even lower radiation doses, ${ }^{16-18}$ the range is still within what is expected for direct effects of radiation exposure and where pneumonitis presents as the major dose-limiting toxicity of TBI. Histologically, the pneumonitis reaction after UHBI or TBI is largely indistinguishable and typically described as interstitial and intraalveolar mononuclear cell infiltrates with varying degrees of edema, hemorrhage, alveolar exudation, epithelial degeneration and hyaline membrane formation. ${ }^{7,19}$ Of note is that chronic pulmonary fibrosis is not documented as a prevalent or life-threatening concern for either UHBI or TBI patients who survive pneumonitis. ${ }^{7,15,20-23}$ Pulmonary complications in accidental radiation exposures are additionally displayed in Figure 1 where the estimated, albeit less defined, radiation 
doses fall within the region expected to produce radiation pneumonitis. ${ }^{23-25}$ The report by Baranov et al ${ }^{23}$ of a victim exposed to a radiation dose estimated at $10 \mathrm{~Gy}$ is particularly remarkable as treatment intervention with transfusions and hematopoietic growth factors allowed hematological recovery and survival through the acute phase with only moderate gastrointestinal toxicity but death from a probable radiation pneumonitis subsequently occurred at 5 months after exposure. Respiratory failure has been similarly reported in other nuclear accidents but where the radiation exposure levels are in a greater range of uncertainty. ${ }^{24,25}$ These aforementioned reports of a delayed but acutely evolving inflammation of the lung defined as pneumonitis in humans rank this tissue as one of the most radiosensitive after the hematopoietic system and serve as a crucial point of reference to the relevance of preclinical animal models in which the whole lung is being similarly irradiated.

\section{REGIONAL LUNG IRRADIATION}

Localized irradiation confined to specific regions of the lung presents as a very different scenario as the unirradiated lung has a major compensatory role in maintaining overall lung function. In this case, the treatments are more pertinent to standard radiation therapy for thoracic malignancies such as lung, breast, and esophageal cancers and lymphomas in which portions of the neighboring lung tissue are included in radiation field. Generally, much higher doses can be tolerated as compared with treatments that involve the whole lung but where there are intimate relationships between tolerance doses and treatment lung volume ${ }^{26-28}$ that have a direct bearing on achieving optimal tumor control with minimal lung toxicity. The presentation of pneumonitis that may be symptomatic and even occasionally fatal after radiation exposure to relatively large lung volumes is well described in the clinical literature..$^{29-33}$ Both clinical and experimental imaging investigations have shown that radiation pneumonitis is co-incident with vascular hypoperfusion within the irradiated lung volume. ${ }^{34-38}$ Although it is tempting to interpret reduced blood flow as a direct consequence radiation damage to the vasculature, other compartmental and adaptive responses of the lung are also expected that maintain a ventilation-perfusion balance such that blood is diverted away from the site of injury to healthy aerated lung tissue regardless of whether the primary cellular insult is of endothelial or epithelial origin. ${ }^{39,40}$ Another hallmark of localized irradiation of the human lung at relatively high doses is the development of chronic pulmonary fibrosis, usually developing after 6 months, which may or may not follow a preceding pneumonitis reaction. In patients receiving thoracic radiotherapy, late fibrosis is usually described radiologically but is mostly asymptomatic. ${ }^{31,41}$ In more extreme cases, it can involve lung shrinkage with intrusion of unirradiated healthy lung by compensatory hypertrophy into the previous radiation treatment field. ${ }^{42-44}$ Chronic lung dysfunction as a whole is usually attributed to loss of overall lung volume. ${ }^{41}$ In rodents as small as mice, regional lung irradiation to comparative small volumes and dose homogeneity becomes more challenging but irradiation to the hemithorax, usually encompassing the whole right lung, is commonly applied among experimental studies and can broadly model compartmental responses of treated vs untreated lungs over a range of radiation doses and without pulmonary lethality. Non-invasive approaches such as computerized tomography ${ }^{45,46}$ or breathing rate ${ }^{47}$ have allowed the continuous monitoring of radiation pneumonitis development and its progression to late effects. At doses as high as $20 \mathrm{~Gy}$ these later effects are seen as a loss of irradiated tissue mass and a compensatory hypertrophy of the shielded unilateral lung. ${ }^{47-49}$ An often neglected but important facet of this late response as reported by Law et al ${ }^{48,49}$ is that while the collagen concentration increases (as determined from hydroxyproline levels), the total amount of collagen present in the irradiated lung tissue actually decreases, an effect that can best be explained as a greater loss of other cellular elements via ischemic atrophy from the aforementioned vascular hypoperfusion. Such a phenomenon of a connective tissue 'concertina effect' has also been described in regional lung irradiation of baboons $s^{50}$ and where accumulations of collagen may still be observed microscopically. The results from these regional lung irradiation studies denote that the appearance of fibrosis following ablative radiation doses can be passive and needs to be distinguished from an active fibrotic process as commonly described in the context of new paradigms in radiation lung damage involving pro-fibrogenic cytokines ${ }^{51-55}$ and where anti-fibrotic strategies as applied to other pulmonary diseases may be ineffectual for ischemic radiation lung damage.

\section{FREQUENCY OF RADIATION STUDIES ON MOUSE LUNG AND THE PREVALENCE OF WHOLE THORAX IRRADIA- TIONS ON THE C57BL/6 MOUSE STRAIN}

Peer-reviewed scientific articles were acquired using publication database sources including but not limited to PubMed, Science Direct, and Google Scholar to create a master database of all papers dealing with effects of ionizing radiation on the lung. In assembling the literature covering 538 papers from 1970 to 2015 on all animal studies, the mouse species was used the most $(65 \%)$ followed by rats $(25 \%)$, dogs and swine $(3 \%)$, rabbits $(2 \%)$, and non-human primates $(1 \%)$. Among the murine studies within this period (357 papers), a large majority utilized whole thorax irradiation (WTI) at $83 \%$ with others using whole body irradiation (11\%), UHBI (1\%), and localized regional lung irradiation (5\%). Thus, $95 \%$ of all mouse studies involve radiation exposure that includes all the lungs that should be related to the experience in humans receiving systemic irradiation in which pneumonitis presents a major life-threatening concern as outlined above. The literature on WTI studies was further subdivided according to the study of different genetic strains. Typical strains used to model radiation effects on lung include $\mathrm{C} 3 \mathrm{H}, \mathrm{CBA}$, and C57BL/6; and the number of papers published per year over 


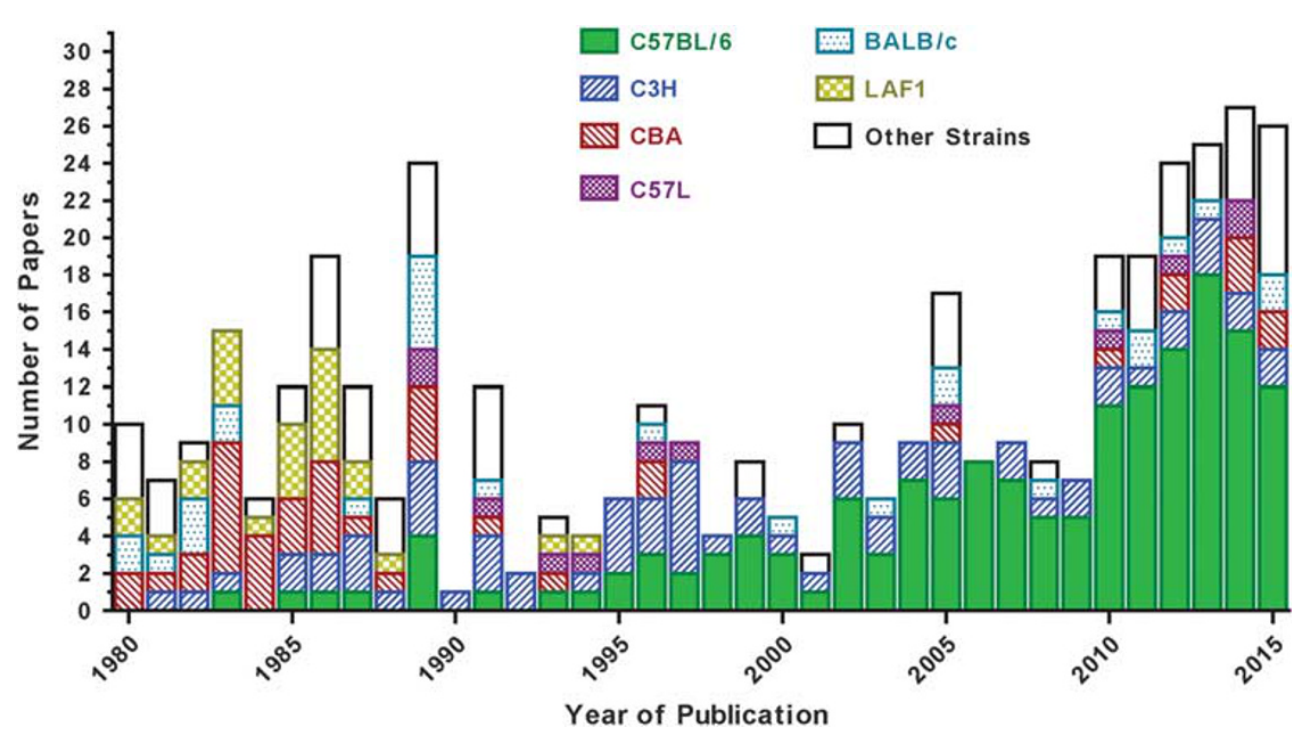

Figure 2 The number of publications per year covering 1980-2015 that studied different mouse strains following WTI. Full references are provided in Supplementary Table 1.

the past 35 years is shown for each of these in Figure 2. Clear changing trends among the different mouse strains with time are apparent in that during the 1980s and 1990s, CBA and $\mathrm{C} 3 \mathrm{H}$ were frequently investigated with fewer studies on C57BL/6 mice while after this period the use of latter strain dramatically increased and has eclipsed the other strains, amounting to $86 \%$ of all published murine lung studies employing WTI in this millennium. A number of contributing factors can explain why the C57BL/6 mouse strain has become so increasingly popular to the present time. The first is that this strain is the most readily available and among the least expensive to purchase. Second, the C57BL/6 mouse has become the standard as a background on which genetic modifications are made and as documented in 22 publications $(17 \%)$ after 2000 as compared with one $(0.7 \%)$ paper $^{56}$ published before 2000. Third, the choice of this strain is often justified as being the 'most characterized' with a selfperpetuating assurance that so many previous studies have been accepted for publication using the C57BL/6 strain. Finally, these animals have been contrasted with other mouse strains in being considered 'fibrosis prone' and steered many of the investigations toward characterizing and preventing this particular pathology.

Nonetheless, these attributes that argue for employing C57BL/6 mice should not pre-empt the crucial question as to whether the model is truly reflective of the clinical scenario which it attempts to emulate. Indeed, whole lung irradiation that simulates half-body therapy, TBI, and accidental radiation exposures to produce radiation pneumonitis in humans (Figure 1) was more reasonably addressed in the earlier studies using the CBA and $\mathrm{C} 3 \mathrm{H}$ mouse strains in being clearly pneumonitis prone, albeit at a moderately higher radiation dose. ${ }^{57,58}$ The justification for replacing these with C57BL/6 mice is less straightforward and has been built on various assumptions behind the underlying events that lead to lethal lung injury as we have discussed below.

\section{MURINE INVESTIGATIONS DURING THE LATENT PERIOD}

Our literature database on whole thorax-irradiated mice has identified studies focused on radiation-induced alterations during the asymptomatic latent phase. Many of these have been driven by the pursuit of predictive biomarkers and in understanding the mechanisms behind the evolution of later lung damage that may then reveal targets for therapeutic intervention before salient lung injury ensues. Some radiation mouse lung studies even consider the measured events as already sufficiently predictive and conclusive as to not extend experiments that capture delayed clinical outcomes and in establishing the utility of the model. A number of different changes within the lung have been documented to occur hours, days, and weeks after radiation exposure. Among the most intensely researched is the local production of certain cytokines, determined either by gene expression or posttranscriptionally by immunohistochemistry. Many of these investigations follow a concept of a continuing cascade of various cytokines that eventually lead to fibrosis. ${ }^{59}$ TNF- $\alpha$ and TGF- $\beta$ are the two most commonly measured cytokines considered respectively to be pro-inflammatory or profibrotic and their relative RNA transcript levels are compiled in Figure 3. This plot is an extension with more recent data of lung cytokine mRNA levels as presented by Hill $^{60}$ who pointed out that while early changes in cytokine levels do occur in the lung, these changes do not follow a clear doseresponse relationship and it is difficult to define exact temporal patterns of cytokine changes. Figure 3 also shows that the cytokine data are also complicated by the large variation among mRNA measurements from different laboratories, with perhaps the greatest variability coming 

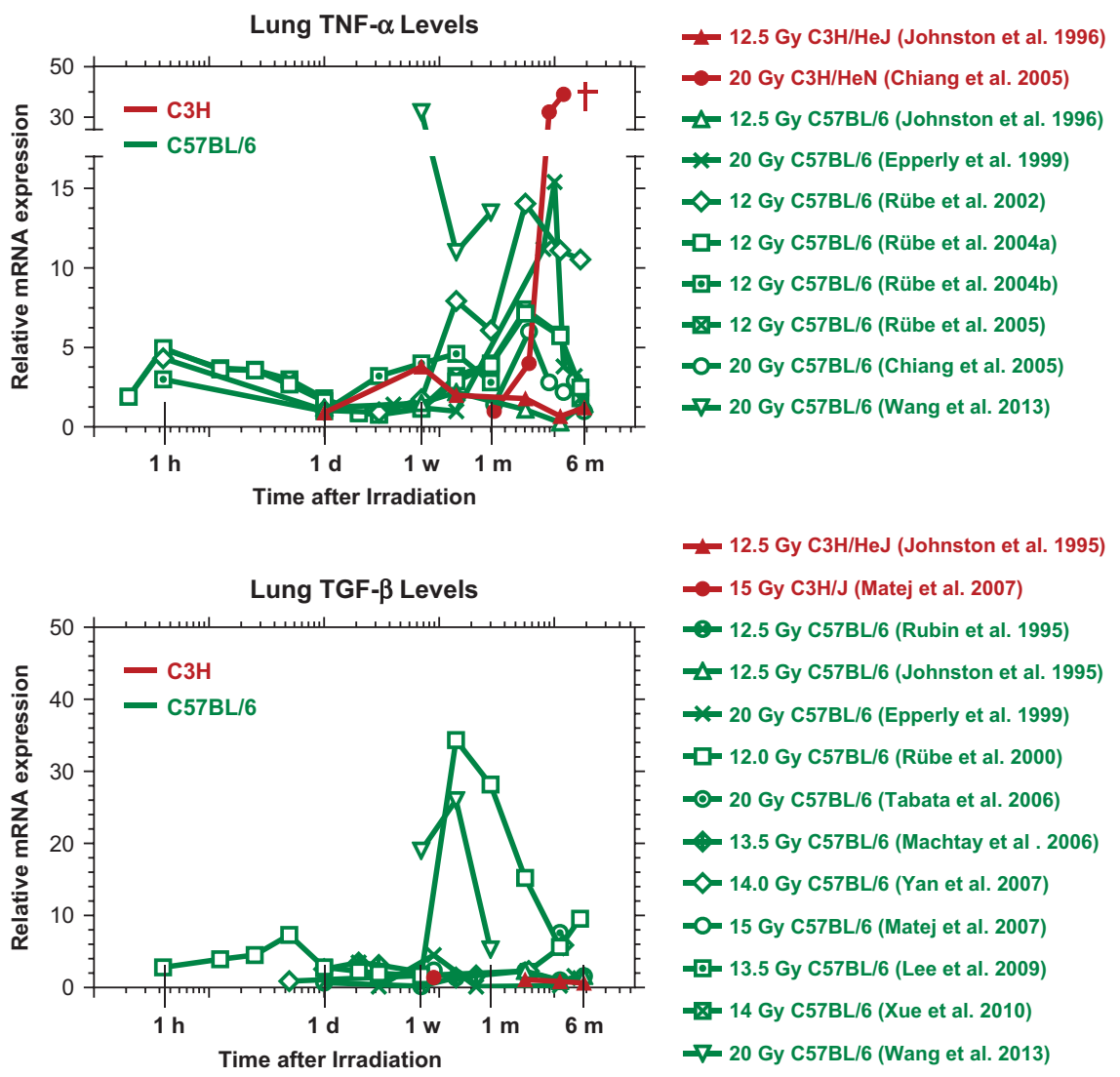

Figure 3 Lung tissue TNF- $\alpha$ and TGF- $\beta$ mRNA levels (relative to unirradiated controls) from different studies in C57BL/ 6 and C3H mice after WTI. Full references are provided in Supplementary Table 1.

from TGF- $\beta$ gene expression measurements. They are also almost entirely performed on C57BL/6 mice, which brings uncertainties in linking such changes to meaningful and relevant end points of delayed lung injury that can be extrapolated to humans. ${ }^{61,62}$ The latter obstacles imposed by using C57BL/6 mice apply to many other early subclinical findings during the latent period including those that have reported cytokine-mediated T-cell and macrophage immune modulation, ${ }^{63-65}$ increased apoptosis, ${ }^{66}$ and indices of oxidative stress. ${ }^{67}$ Studies on other mouse strains that are closer to humans in being more susceptible to latent pneumonitis can, however, yield more conclusive interpretations. Modifying radiation effects can further robustly establish whether the early supra-acute events in the irradiated lung are independent or have a causal relationship with true radiation pneumonitis. In the case of using pneumonitis-prone $\mathrm{C} 3 \mathrm{H} / \mathrm{HeN}$ mice, for example, bronchial alveolar lavage (BAL) can show an inflammatory cellular and cytokine response but this is subsided by the time of onset of pneumonitis. ${ }^{68}$ Furthermore, treatment with dexamethasone can temporarily suppress early radiation-induced pro-inflammatory cytokine gene expression but the drug course did not modify the later pneumonitic process. ${ }^{69}$ Increased surfactant levels in BAL from release by type 2 pneumocytes can similarly arise by 1 day after irradiation, ${ }^{70}$ but comparisons among different mouse strains and other species as well as with high LET neutron irradiation showed that it poorly predicts changes in later pneumonitis-related mortality. ${ }^{71}$

In considering how these mouse studies conducted at early assay times can relate to later injury as also experienced in humans, an important aspect that makes radiation effects unique and very intriguing as compared with many other cytotoxic insults to the lung is that it still takes months before overt pathology and pulmonary dysfunction manifest. Also, remarkable is that this symptomatically silent period is followed by the rapid evolution of radiation lung injury as an acute life-threatening inflammatory reaction rather than as a gradual and continuing process. The lung can also be compared with other normal tissues as the classical inverse relationship between the rate of cell turnover and the time one needs to wait before seeing expression of radiation injury still stands. ${ }^{72}$ Much of the radiation damage appears to emanate from the alveoli where the resident epithelial and endothelial cells have a relatively slow renewal rate, ${ }^{73-76}$ and the delayed injury is more consistent with radiation sterilization through reproductive failure or cell senescence than through early apoptotic cell death. ${ }^{77}$ In this context, there are a number of papers in which severe lung injury leading to 
mortality can be brought forward as well as enhanced to drastically shorten the latency period. This is typically seen experimentally following the combination of lung irradiation with cytotoxic drugs such as bleomycin and cyclophosphamide ${ }^{78,79}$ as these drugs can elicit more immediate cell damage in the lung followed by stimulated proliferation and precipitation of radiation injury. A similar phenomenon has been reported following the pretreatment with butylated hydroxytoluene and only at a time when radiation was delivered at the time of type 2 pneumocyte but not endothelial cell proliferation. ${ }^{80}$ Other scenarios of accelerated radiation injury to the mouse lung have been observed with concomitant allogeneic graft $v s$ host disease ${ }^{17}$ or influenza infection $^{81}$ and point to the necessity for experiments to cover combined injuries in which the time course of pulmonary pathology has been precociously modified beyond simple dose enhancement of radiation toxicity.

\section{DEVELOPMENT OF DELAYED AND STRAIN-DEPENDENT MORTALITY}

Approximately half of all research papers on mouse WTI over the past 35 years have employed lethality as a presumed end point of severe lung injury $(61,53$, and $45 \%$ for studies published in the 1980s, 1990s, and 2000-2015, respectively). All had study lengths that exceeded 2 months out to at least 6 months and required sufficiently high radiation doses to produce mortality. With respect to the radiation dose levels used, some of these are disturbingly high in exceeding $15 \mathrm{~Gy}$ as used in 50\% of all WTI papers published in 2001-2015 and $84 \%$ of these were performed on C57BL/6 mice.

We have assembled the median survival time (MST) estimates from a total of 41 articles in our database that presented survival data and where the WTI treatment produced an excess of $50 \%$ mortality. These values are plotted in relation to the radiation dose in Figure 4 for male and female $\mathrm{C} 57 \mathrm{BL} / 6, \mathrm{CBA}, \mathrm{C} 3 \mathrm{H}$, and $\mathrm{C} 57 \mathrm{~L}$ mice to provide a number of insights as to how the MSTs depend on mouse gender and strain. Overall, the survival data on C57BL/6 mice come from the largest number of institutions that may account for the greatest variability and stresses the need for controlling other differences in experimental conditions among the different laboratories such as radiation dosimetry, type and field geometry, mouse age, microbiological status, and animal vendor. The data points also confirm the use of excessive radiation doses for WTI (above $15 \mathrm{~Gy}$ ) by many investigators that can mask strain-related differences in radiosensitivity, as exemplified by similar MSTs at a single dose level of $18 \mathrm{~Gy}$ in BALB/c strain ${ }^{82}$ that is nevertheless well recognized as having a high radiosensitivity from lethality at doses as low as $10 \mathrm{~Gy} .{ }^{62,80,83,84}$ In spite of the high variability in the data as assembled from the different reports in the literature, significantly longer and radiation dose-dependent MSTs are seen in male as compared with female C57BL/6 mice (Figure 4a). This sex difference is substantiated also within the same laboratory and study by Travis et al ${ }^{85}$ where the MST in males following 16 Gy WTI is lengthened from females by a further 2 months. The presentation of radiation dose-dependent MSTs for CBA, C3H, and C57L mouse strains contrasted from C57BL/6 mice in showing less effect of mouse gender (Figure $4 \mathrm{~b}$ ). The MSTs were also shorter (corresponding to radiation pneumonitis) in these strains as previously reported. ${ }^{57,61}$ The upward increase in MSTs in CBA and $\mathrm{C} 3 \mathrm{H}$ mice at doses of below $15 \mathrm{~Gy}$ corresponds to the change from pneumonitis to an even later phase of pleural effusions in these strains that will be discussed further below.

Figure 5 displays how the above radiation dose-MST profiles according to mouse strain and sex compare with latencies to radiation pneumonitis experienced in patients receiving a range of absorbed UHBI doses to the whole lung ${ }^{8}$ and in rhesus macaques treated with graded doses of WTI. ${ }^{13}$ Of note is that the mean time to pneumonitis in UHBI patients has a relatively wide range at each radiation dose as would be expected from greater genetic and environmental variations experienced in humans. Nonetheless, comparison with the murine studies reveals that MSTs fall either within or outside this range. The protracted MSTs in both female and male C57BL/6 mice showed the largest difference while the shorter latencies at low radiation dose in C57L mice overlapped with the timing of pneumonitis in humans and monkeys. Apart from further supporting our recent argument that $\mathrm{C} 57 \mathrm{~L}$ mice are the closest to radiation lung damage in primates, ${ }^{62,86,87}$ the similarities in latency provide a basis for comparing similar underlying mechanisms that govern the kinetics of radiation injury for more reliable preclinical determination of predictive biomarkers and administration of therapeutics.

\section{ASCRIBING THE CAUSE OF MORTALITY AFTER LUNG IRRADIATION}

Our literature database was further scrutinized with attention to how investigators witness and interpret the underlying cause of lethal injury in mice after WTI. Very few perform or document gross pathology on terminal animals that enter respiratory failure. Instead, these papers relied on making assumptions based on previous literature reports, and thus the chronology of how researchers based their perceptions of the types of lung injury as being responsible for preventing survival merits thoughtful and critical analysis. Notably, the earlier studies performed in the 1970s and 1980s were more frequently applied to $\mathrm{C} 3 \mathrm{H}$ and $\mathrm{CBA}$ mouse strains (Figure 2) and, as already discussed, these justifiably focused on radiation pneumonitis as being closer to modelling the same pathology in humans under comparable wide-field irradiation conditions. These strains are well described as exhibiting two phases of respiratory dysfunction and mortality. During the period of 3-6 months, the autopsied lungs of terminal CBA or $\mathrm{C} 3 \mathrm{H}$ mice consistently show extreme reddened consolidation or 'hepatization' and marked increases in tissue mass together with widespread and severe histological changes typical of inflammatory pneumonitis. ${ }^{61,88,89}$ On the other hand, the 

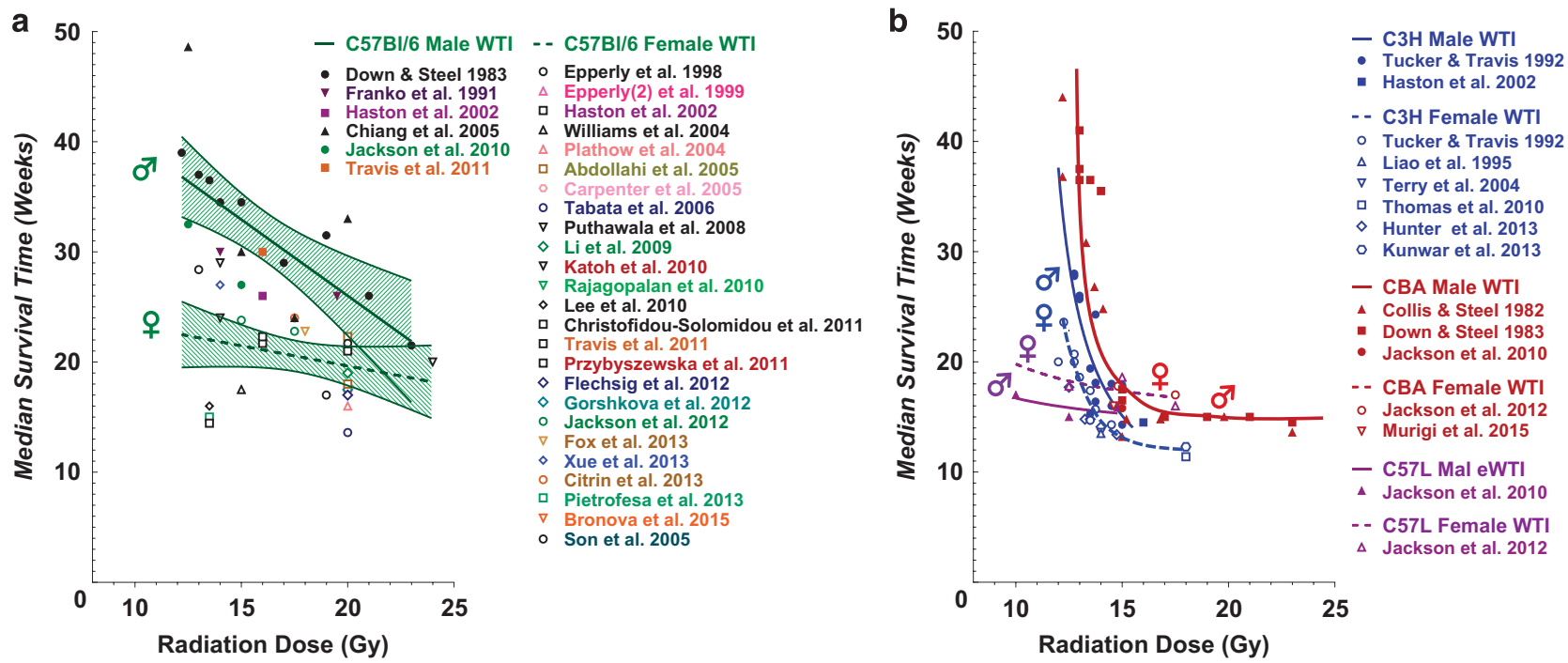

Figure 4 Median survival times (MSTs) of different mouse strains as a function of prescribed WTI dose assembled from different published studies. (a) C57BL/6 male (closed symbols) and female (open symbols) were separately fitted using linear regression with $95 \% \mathrm{Cl}$ envelopes to show significantly longer MSTs in males at doses of below $20 \mathrm{~Gy}(P=0.015)$. Separate linear regression analysis of this data set on $\mathrm{C} 57 \mathrm{BL} / 6$ mice did not show a significant effect of age at treatment covering 6-28 weeks ( $P=0.632$ and 0.343 for males and females, respectively). (b) Other strains $(\mathrm{CBA}, \mathrm{C} 3 \mathrm{H} / \mathrm{HeJ}, \mathrm{C} 3 \mathrm{Hf} / \mathrm{Kam}$, and $\mathrm{C} 5 \mathrm{~L}$ ) showed less variation between separate studies and between sexes and produced similar MSTs at 15-20 weeks after WTI. Full references are provided in Supplementary Table 1.

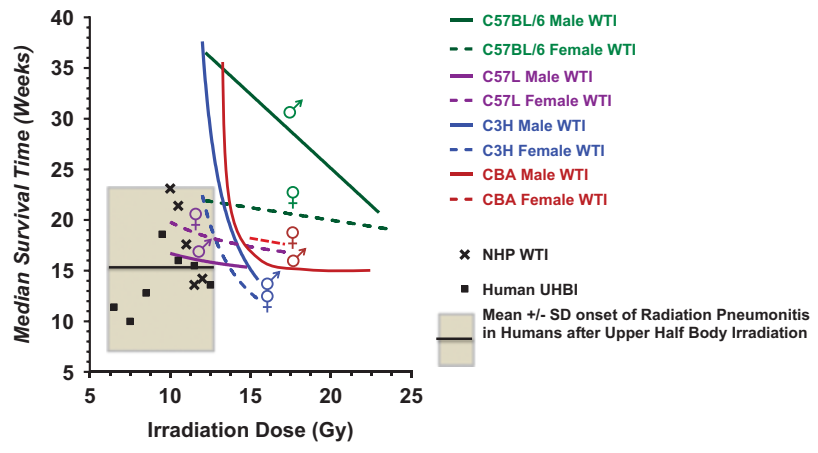

Figure 5 Differing latencies to severe lung injury according to radiation dose exposure to the whole lungs of mice (curves derived from Figure 4), non-human primates, and humans. The C57L mice show the closest overlap with the region of radiation pneumonitis in patients receiving $\mathrm{UHBI}^{8}$ as well as non-human primates (NHP) following WTI. ${ }^{13}$

pathology as described in C57BL/6 mice has been more ambiguous with many researchers (55\% covering 1970-2015) attributing mortality to pulmonary fibrosis. The switch to using $\mathrm{C} 57 \mathrm{BL} / 6$ over $\mathrm{C} 3 \mathrm{H}$ or $\mathrm{CBA}$ mice at around the turn of the millennium (Figure 2) coincides with publications that addressed diverse radiation responses of the lung among different genetic mouse strains. The most often cited papers to support assigning C57BL/6 mice as being susceptible to radiation-induced pulmonary fibrosis are those of Sharplin and Franko ${ }^{58,90}$ and Dileto and Travis, ${ }^{91}$ which deserve careful consideration as to the actual data that were presented. These were primarily histological evaluations that did indeed document increased collagen deposition in C57BL/6 mice after WTI that was absent in comparably treated $\mathrm{C} 3 \mathrm{H}$ or CBA strains. It is especially notable that the fibrosis was often accompanied by inflammation typical of pneumonitis, in which Dileto and Travis ${ }^{91}$ termed 'fibrosing alveolitis' and in quantifying the area of the lungs presenting with fibrotic lesions, the results were quite variable with an average of only about $5 \%$ of the lung sections being affected in mice experiencing respiratory failure that presage death. Similar observations of focal and variable fibrosis covering a relatively low percentage of the lung area have been confirmed in later studies on this mouse strain. ${ }^{61,85,92,93}$ While the early paper by Sharplin and Franko ${ }^{90}$ categorized C57BL/6 mice as having 'extensive fibrosis', a subsequent paper from the same group re-considered this definition as saying 'the degree of fibrosis was substantially less severe than in C57L/J'. ${ }^{83}$ Both Sharplin and Franko ${ }^{58,89}$ and Dileto and Travis ${ }^{91}$ acknowledged that the incidence and latency of mortality after WTI was similar to another substrain of male C57BL/6 mice as first reported by Down and Steel. ${ }^{57}$ In this latter case, however, no fibrosis was observed histologically in terminal mice.

The literature contains a number of papers that have assessed both mortality and the degree of fibrosis (from histological quantification or hydroxyproline content) as a result of WTI and many of these show only a coincidental relationship. The connection between fibrosis and mortality can be more confidently evaluated from seeing whether they strictly follow one another under conditions of modifying radiation effects. Table 1 lists the instances in which therapeutic or genetic intervention can effectively dissociate 
Table 1 Situations of dissociation of radiation-induced pulmonary fibrosis from lethality in mice after WTI

\begin{tabular}{|c|c|c|c|c|c|}
\hline Comparison & Mouse strain & Radiation dose & Effect on lethality & Effect on fibrosis & Reference \\
\hline WR2721 (Amifostine) treatment & CBA & 13-19 Gy & $\begin{array}{l}\text { Protection greater for late } \\
(>6 \mathrm{~m}) \text { than early }(<6 \mathrm{~m})\end{array}$ & Less for late $(>6 \mathrm{~m})$ by hydroxyproline & 94 \\
\hline WR2721 (Amifostine) treatment & $\mathrm{C} 3 \mathrm{H}$ & 4-16 Gy (split dose) & $\begin{array}{l}\text { Protection greater for late } \\
(>6 \mathrm{~m}) \text { than early }(<6 \mathrm{~m})\end{array}$ & Less for late $(>6 \mathrm{~m})$ by hydroxyproline & 95 \\
\hline avß6-deficiency & C57BL/6 & 14 Gy & None & Reduced by histology and hydroxyproline & 96 \\
\hline anti-av $\beta 6 \mathrm{mAb}$ treatment & $\mathrm{C} 57 \mathrm{BL} / 6$ & 14 Gy & None & Reduced by histology and hydroxyproline & 96 \\
\hline rsTGF- $\beta$ RII-Fc treatment & C57BL/6 & 14 Gy & None & Reduced by histology and hydroxyproline & 96 \\
\hline ICAM-1 deficiency & C57BL/6 & 14-18 Gy & None & Reduced by hydroxyproline & 97 \\
\hline PEG-AOE treatment & C57BL/6 & 13.5 Gy & None & Reduced by histology and hydroxyproline & 98 \\
\hline DF2156A treatment & KKVHIJ & 14 Gy & None & Reduced by histology & 99 \\
\hline
\end{tabular}

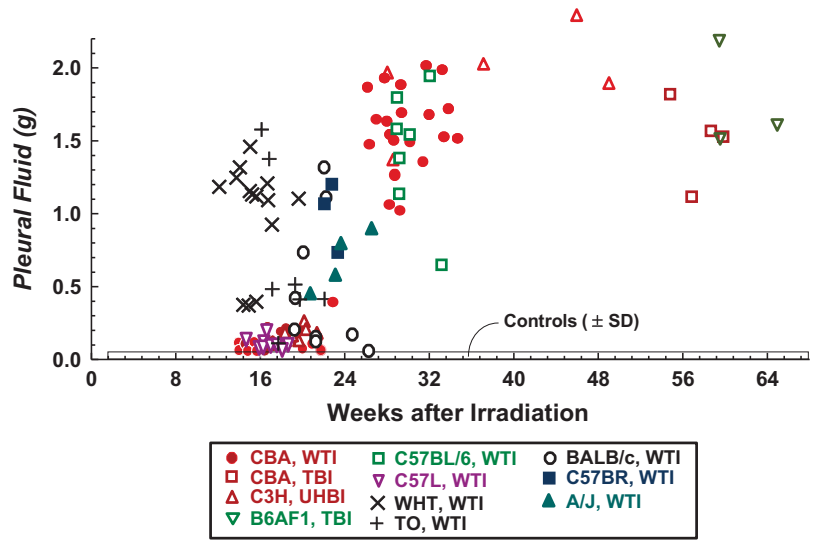

Figure 6 Pleural fluid levels at autopsy in individual terminal mice of 10 different strains following radiation treatments that include the whole lung. The treatments include whole thorax irradiation (WTI), upper half body irradiation $(\mathrm{UHBI})$, and total body irradiation with syngeneic bone marrow transplant rescue (TBI). Terminal animals with low pleural fluid levels had increased lung tissue mass ( $>250 \mathrm{mg}$ ) indicative of lethal pneumonitis while those animals presenting with effusions beyond 6 months had normalized lung weights $(<250 \mathrm{mg})$. Five strains (BALB/C, C57BR, A/J, WHT, and TO) showed a mixture of both early pleural effusions and pneumonitis. The existing data are incidentally all from male mice compiled from six separate studies. ${ }^{47,61,62,89,107,108}$

mortality from fibrosis to denote that some other intervening lethal pathology is involved. ${ }^{94-99}$ For the studies performed on CBA mice, the two independent phases of injury as defined by elevations in breathing rate and mortality were initially interpreted as pneumonitis that was then followed by fibrosis beyond 6 months. ${ }^{100-102}$ Subsequent studies, however, have consistently reported that CBA mice exhibit at least very mild fibrosis, in contrast to observations made in C57 mouse strains. ${ }^{47,61,90,94}$ Autopsy examinations in irradiated CBA mice show normalized lung tissue mass but the appearance of large pleural effusions became the dominant feature during the late phase. ${ }^{61,88,94}$

\section{THE COMMON BUT NEGLECTED PROBLEM OF PLEURAL EFFUSIONS}

Although there has been copious attention to pulmonary fibrosis in irradiated C57BL/6 mice, only a few studies in the literature have actually attempted to evaluate or consider the role of pleural effusions on mortality in this strain. This is in spite of early reports in the 1970s and 1980s of radiationinduced pleural effusions in a number of mouse strains that account for decreased survival. ${ }^{57,88,89,94,103-107}$ The intimate relationship between pleural fluid levels and lung dysfunction was rigidly tested in CBA mice during the late phase at beyond 6 months and under radiation dose-effect modification by the radioprotector amifostine and by protracted lowdose rate irradiation. ${ }^{88,94}$ Other strains, however, respond differently with time. Figure 6 gives a compilation of all studies in which pleural fluid levels were quantified at the time of autopsy in terminal mice. This includes data from 10 different mouse strains in radiation experiments conducted at 4 separate institutions to show high and debilitating levels of pleural fluid (above $1 \mathrm{~cm}^{3}$ ) in many of the animals. These pleural fluid levels do not always follow measurement of lung mass as an index of pneumonitis and identify mouse strains that can be separated in having a relatively early incidence of effusions (eg, BALB/c, WHT, TO, C57BR, and A/J mice) while other strains show that effusions arise separately and much later (eg, $\mathrm{C} 3 \mathrm{H} / \mathrm{HeJ}$ and CBA mice). Importantly, male C57BL/6 mice fall in-between in having a mixed pleural effusion and delayed pneumonitis as initially described by Down ${ }^{108}$ and subsequently confirmed by Jackson et al. ${ }^{61}$ While previously categorized as being similarly susceptible to fibrosis, ${ }^{90}$ the C57L strain differs remarkably from C57BL/6 mice in exhibiting a very high sensitivity to radiation pneumonitis with MSTs that fall within latency times and radiation doses experienced by patients and NHPs (Figure 5). C57L mice are also the only strain so far reported that do not present with pleural effusions (Figure 6), at least for animals that survive out to 9 months post WTI. ${ }^{86}$ This mouse strain 
does indeed present with focal areas of pulmonary fibrosis after the resolution of pneumonitis and while not lethal appears to continually impair lung diffusion capacity (DLco). ${ }^{109}$ Interestingly, C57L mice can be distinguished from fibrosis-resistant $\mathrm{C} 3 \mathrm{HeB} / \mathrm{FeJ}$ mice in showing more production of TGF- $\beta .^{110}$

Incidentally, pleural fluid data as shown in Figure 6 so far exist only for male mouse strains. Given that female C57BL/6 mice stand out as having a shorter latency to mortality as compared with males (Figure 4a), it becomes especially important to investigate whethere this is from accelerated pneumonitis or pleural effusions or both.

From the above considerations spanning many decades of research on thorax irradiated mice, it can now be established that pleural effusion is a very significant complication that is independently expressed from pneumonitis or fibrosis but still has the cause and effect relationship in compressing the lung to reduce its volume and producing increased breathing rate and lethality. While histological analysis may appear to provide more direct evaluations of pathological changes within the lung, the lethal accumulations of pleural fluid may seriously interfere with capturing the full development of pneumonitis/alveolitis $v s$ fibrosis. This intrusion therefore compromises those studies in which pleural effusions are neither considered nor documented yet still depend on histological criteria to define genetic determinants of radiation lung damage among different recombinant mouse strains. ${ }^{64,82,92,93,111}$

The actual origin of radiation-induced pleural effusions remains elusive in spite of its high recorded frequency in mice but some possibilities can be proposed and used as a basis for future investigations. First, pleural effusions can be circumvented by shielding the left hemithorax and allow the full spectrum of pathologies to develop unhindered in the irradiated right lung and reveal a slower progression of pneumonitis in male C57BL/6 as compared with CBA mice. ${ }^{47}$ Localized irradiation of other regions of the mouse thorax, while challenging, may isolate the cause of effusions. In the study of Liao et al, ${ }^{112}$ different radiation fields were used in $\mathrm{C} 3 \mathrm{Hf} / \mathrm{Kam}$ mice and differences in regional sensitivity were described that were assumed to be related to lethal pneumonitis. This paper also noted that 'pleural effusion was often found in the sick animals when killed' but the implications of this finding were not discussed and it remains unknown how its incidence varies according to the size and region of the radiation-exposed thorax. Similarly, regional irradiation of the thorax in rats have been performed and pleural effusions have been described as occurring earlier than in mice and where it is often accompanied by cardiovascular disease and appears more prevalent if the heart is included in the radiation field. ${ }^{113,114}$ Second, the incidence of pleural effusion, while not prevalent, can occur in patients receiving thoracic radiotherapy ${ }^{29,115,116}$ but has not been reported following clinical UHBI. ${ }^{6-9}$ The reasons for its relatively low frequency following clinical radiotherapy remain uncertain but may perhaps be attributed to its prevention by standard care of patients experiencing radiation pneumonitis such as treatment with corticosteroids and this appears as a very relevant and fruitful area of investigation in mice. The occasional literature that does report radiation-induced pleural effusions in humans points to impaired lymphatic drainage of the pleural space. ${ }^{117-119}$ The possibility that this may be the culprit in generating effusions in mice is supported by the recent observation in the female C57BL/6 strain of a decline in the density of lymphatic vessels of subpleural and interstitial lymphatics following WTI. ${ }^{120}$ Finally, there is a clear impression from rhesus macaques that pleural effusions accompany radiation lung injury after high doses of WTI. ${ }^{13}$ How this relates to the origin of effusions in rodents and whether this can be extrapolated to humans has yet to be fully explored.

\section{IMPLICATIONS FOR SELECTING THE BEST MODELS IN THE PRE-CLINICAL EVALUATION OF THERAPEUTICS}

Our survey of papers in the literature from 1970 to 2015 indicated that $56 \%$ of mouse WTI studies using mortality as an endpoint also investigated putative radioprotecting (given before or close to radiation treatment) or radiomitigating agents (given post-irradiation). Those papers that investigate mitigators are listed in Supplementary Table 2 to show that $62 \%$ of these have been performed on C57BL/6 mice. This also shows that most (83\%) terminate the experiments by 6 months and can observe a therapeutic effect as higher survival at that moment in time but do not address longer term toxicities. Ideally, a therapeutic should be proven to actually prevent both pneumonitis and fibrosis using welldefined and relevant end points and models. This has only on rare occasions been demonstrated in CBA mice for radioprotection by amifostine ${ }^{94,95}$ while the majority of survival studies in C57BL/6 mice have not established whether the treatment actually prevents a particular injury or has simply delayed its expression to beyond the study period. Our survey on mitigation studies also shows that nearly all are confined to only one mouse strain. Only two reports have included strain comparison (among $\mathrm{KK}, \mathrm{AKR}$, and $\mathrm{C} 3 \mathrm{H}$ mice) and show that the extension of MSTs upon treatment with imatinib mesylate ${ }^{121}$ or the CXCR antagonist G3IP ${ }^{122}$ can vary 2- to 3 -fold among the different strains.

The degree by which a therapeutic agent can alter the radiation response of the lung should also be considered in terms of how it depends on the radiation dose level as this may vary according to the incidental exposure from a nuclear device or to prescribed treatments in radiotherapy. The data presented in Figure 4 already show how the survival times can vary dramatically on changing radiation dose and that these can encompass more than one type of pathology. For those studies in which radiation mitigators have so far been tested, only three, involving investigations on methylprednisolone in CF1 mice, ${ }^{123,124}$ D-penicillamine in Sch(ICR)BR mice, ${ }^{125}$ and celecoxib in $\mathrm{C} 3 \mathrm{Hf} / \mathrm{Kam}$ mice ${ }^{126}$ have employed more than 
one radiation dose level. A full appreciation of any modifying effect can be accomplished in experimental study designs that deliver graded radiation doses for each arm for construction of dose-response relationships. Valuable quantitative parameters may then be obtained to evaluate how a particular therapy affects both the position and slope of the curve with estimation of dose-reduction factors (DRFs) and any given level of biological effect. The application of statistically robust curve fitting analysis such as probit or logit can additionally provide guidance in designing studies using optimal dose increments and manageable animal numbers. ${ }^{127}$ While most dose responses given for many types of normal tissue injury have used lethality (eg, for derivation of LD30, LD50, and LD70), iso-effect doses can be similarly generated from more specific end points of lung injury, as demonstrated by the radioprotective effects of amifostine on radiation dosedependent changes in breathing rate as well as mortality in CBA and C3Hf/Kam mice. ${ }^{94,95,102,128}$

While no results showing efficacy of any putative therapeutic has yet been published in the C57L mouse strain, more recent studies have argued that preclinical testing of protecting or mitigating agents in C57L mice can be better translated to effects in humans as compared with many other mouse strains. ${ }^{14}$ In particular, the very steep dose-response curve for mortality in C57L mice clearly reflects radiation pneumonitis occurring at expected times and is positioned close to the high sensitivity of the lungs as experienced by UHBI patients (Figure 5). The fact that no incidence of late mortality occurs after resolution of pneumonitis in surviving animals, at least out to 9 months after WTI or TBI, ${ }^{61,86,109}$ then this end point would need to be supplanted by noninvasive functional and/or imaging assays and histology to establish how any therapeutic effect can be extended to late pulmonary fibrosis. A major and over-riding problem with the utilization of C57L mice, however, is their very limited availability and high cost that prohibits routine application in research projects aimed at selecting the most promising therapies for further testing in large animal models and humans.

\section{CONCLUSIONS AND AREAS FOR FURTHER RESEARCH}

It is well recognized from clinical experience that intrinsic variability among patients has a significant role in treatment outcome and brings in the need to explore genetic factors that determine the severity of radiation lung damage. ${ }^{129}$ The diverse radiation responses of the lung according to mouse strain have been emphasized from the 2008 CMCR workshop to establish standardized animal models for assessing agent efficacy in a number of relevant tissues and organs ${ }^{3}$ and led to the recommendation that at least two genetic strains be used since it is presumed that they may represent the extremes of the range of human lung responses to radiation damage. Genetically inbred mouse strains also limit experimental variability but the collective range of responses in those strains so far studied may not necessarily emulate the heterogeneous nature of the human population. In the case of the high lung radiosensitivity of C57L mice relative to many other mouse strains, the timing and radiation levels to produce lethality appear to be the closest to the average responses seen in both adult humans and NHPs (Figure 5). In coming to the title of this literature review on radiation lung models in mice, what is the good, the bad, and the uncertain? Before answering such a question we should always keep in mind that while no particular animal model is ideal, we can still rationalize that some are less ideal than others. The least ideal model may therefore be considered as generally 'bad' and this is reasoned to be radiation lung studies using mouse strains and end points that do not fully account for long delays in expressing pulmonary injury as well as a variable and complicated picture of mixed pathologies that include pleural effusions. As already conceptualized by Jackson et al, ${ }^{62}$ this problem may indeed lead either to an over-estimation of a therapeutic effect by preventing lethal but less relevant pleural effusion or to an under-estimation if pleural effusions continue to shroud true prevention of radiation injury within the lung. Nonetheless, the unusual prolongation of radiation pneumonitis in male C57BL/6 mice as best shown in regional lung irradiation studies is a fundamentally important phenomenon that may prove useful in resolving the pathogenesis of radiation damage to the lung. It is less clear how female C57BL/6 stands on differing latencies as there is so far little understanding as to how the timing of pneumonitis and/or pulmonary fibrosis develops in relation to effusions. Overall, females appear to show a shorter course to lethality by about 2 months (Figure $4 \mathrm{a}$ ) that bring them closer to what we would expect in humans. A crucial question is to whether the earlier incidence of mortality in female as opposed to male C57BL/6 mice is from accelerating pneumonitis forward in time that better separates this from pleural effusions and would therefore makes this a more acceptable preclinical model. No clear sex differences in terms of MSTs are seen for CBA, C3H, or C57L mouse strains (Figure $4 \mathrm{~b}$ ) and no dramatic gender effect on radiation lung toxicity has yet been documented in patients receiving systemic radiotherapy. For patient cohorts given localized thoracic radiotherapy, female gender was significantly predictive of radiation pneumonitis in some but not in all studies. ${ }^{130-134}$

Another 'bad' aspect identified from this literature review is the high reliance on the lethality end point in the majority of mouse lung studies and where it is used as the primary criteria for evaluating therapeutics. This has, in part, been encouraged by interpretations of the FDA 'Animal Rule' wherein it states, and with some ambiguity, that 'The animal study endpoint is clearly related to the desired benefit in humans, generally the enhancement of survival or prevention of major morbidity'. ${ }^{4} \mathrm{We}$ found that the majority of these research articles (75\%) made presumptions on the cause of mortality but without establishing through pathology on terminal animals what is actually responsible. This is exemplified by the frequent 
assumption that pulmonary fibrosis is the leading cause of mortality in C57BL/6 mice while there is little to support this from those studies that follow autopsies on mice entering respiratory failure. Moreover, there are a number of other examples of mouse studies that dissociate lethality from direct assessments of fibrosis upon modifying radiation damage (Table 1). A 'good' approach is to replace lethality as a primary end point with the application of non-invasive, quantifiable and lung-specific measures of radiation injury in addition to histopathology. This can be met by assays of breathing rate and CT lung density that provide well-defined radiation dose-response curves and estimation of iso-effect dose values for different treatment scenarios. ${ }^{61,86,88,94,100,102}$ In keeping with the spirit of the three 'Rs' of animal experimentation, ${ }^{135}$ these end points enable a refinement of animal use as well as being transferable to the clinical evaluation of lung injury in humans. In addition, the lower biological variability in $\mathrm{C} 57 \mathrm{~L}, \mathrm{CBA}$, and $\mathrm{C} 3 \mathrm{H}$ mouse strains together with a reconsideration of statistical analysis to radiation dose-response curves ${ }^{127}$ can allow the reduction of treatment group size and relieves the burden of performing resource-intensive indices of radiation lung damage. In recognizing the C57Ls as the 'good' and so far the most desirable to be considered in pre-clinical testing, investigators are still faced with the logistical problem of obtaining sufficient numbers of this strain to meet their research objectives as these mice are renown in having limited availability as well as high purchase costs. The C57L strain is not alone in having a high sensitivity as BALB/c mice are recorded to have a comparable low LD50 at 6 months following WTI ${ }^{62,80,82,84}$ that is most likely attributed to a general deficiency in DNA repair through lowered DNA-PK activity. ${ }^{136} \mathrm{BALB} / \mathrm{c}$ mice should, however, be used with caution in that they also bring a problem of early pleural effusions (Figure 6). ${ }^{62}$ One recent paper on the $\mathrm{FVB} / \mathrm{N}$ strain suggests a similarity with C57L mice in showing both lethality from pneumonitis at doses as low as $12 \mathrm{~Gy}$ followed by fibrosis at $11 \mathrm{~Gy}{ }^{137}$ This may therefore be worthwhile to investigate further as a possible alternative in being both more readily available and as a background on which many transgenic mice are created. Studies on $\mathrm{CBA}$ or $\mathrm{C} 3 \mathrm{H}$ mice are also reasonable strains for use in preclinical lung studies in at least showing a discrete pneumonitis while later effusions still need to be carefully monitored as an independent feature that diminishes the relevancy of the model to humans. Apart from being routinely available from routine vendors, CBA and $\mathrm{C} 3 \mathrm{H}$ mice can be used that model a higher resistance to radiation pneumonitis with little subsequent pulmonary fibrosis.

Without retracting from the need to properly extrapolate data obtained from mice to humans, the wide range and type of radiation responses that cover the breadth of many mouse strains can provide a valuable platform for mechanistic studies and in resolving key genetic, cellular, and molecular determinants. Lung studies on mice with specific genetic modifications have clearly become a powerful experimental tool in this endeavor but nearly all are unfortunately on the 'standard' C57BL/6 background strain where it remains unclear how the addition and deletion of genes in comparison with wild-type control mice can offer a reliable interpretation of the data with full consideration of the different types of pathology that determines the outcome. Pending a much needed and more complete characterization of earlier expression of radiation injury in female C57BL/6 mice, a compromise may be reached by restricting genetic studies to this gender. Another possible solution to bringing in transgenic traits into a radiation lung model is to use F1 hybrid mice derived from C57BL/6 $\times$ C57L breeding after first establishing whether the desired radiobiological phenotype from the C57L parent is sufficiently retained. This hybrid cross could also possibly overcome the low breeding performance of the inbred C57L mouse strain. Regardless of what particular mouse strain or genetic manipulation thereof is selected, there is still the desire to avoid the intrusion of lethal pleural effusions. This can be accomplished using unilateral hemithorax irradiation where the full spectrum of lung injuries can be continuously monitored from available functional and imaging methods as well as from standard histopathology. ${ }^{45-47}$ The more localized radiation treatment of the lung also better simulates the conditions as encountered in oncology patients receiving targeted radiotherapy to the thorax. Further improvement of the mouse model in this instance has come from the arrival of small animal imageguided X-ray platforms ${ }^{138,139}$ as these can provide more precise irradiations of different volumes and regions of the lung and address topical issues of interest to altered lung tolerance in radiation oncology patients. ${ }^{26-28}$

To summarize our conclusions gathered from reviewing as extensively as possible the current literature on radiation injury to the mouse lung, we come to the overall impression that experimental studies on C57BL/6 mice are often popularized but with the misconceptions that radiationinduced pulmonary fibrosis is the primary clinical concern and that this leads to ultimate mortality after WTI. Furthermore, we have provided a chronologic account as to the changing trends in selecting a particular mouse model and that these changes do not necessarily meet the need to have the most clinically relevant end points. In this context, we can identify $\mathrm{C} 57 \mathrm{~L}, \mathrm{CBA}$, and $\mathrm{C} 3 \mathrm{H}$ strains as pneumonitis-prone mouse models that currently provide a reasonable representation of pulmonary complications in humans after whole lung irradiation. It is less certain how the utility of the radiation lung model in either male or female C57BL/6 mice stands in generating preclinical data and demands greater diligence in evaluating the various types of tissue injury as they impact on any particular end point. Future comparisons among all these and other genetic strains using existing non-invasive assays of pulmonary pathophysiology can additionally provide opportunities to explore the key phenomena that determine lung radiosensitivity and to finally address the long-standing 
question as to how acute pneumonitis and later chronic fibrosis follow along proposed mechanistic principles and whether they are truly inter-connected.

Supplementary Information accompanies the paper on the Laboratory Investigation website (http://www.laboratoryinvestigation.org)

\section{DISCLOSURE/CONFLICT OF INTEREST}

The authors declare no conflict of interest.

1. Coggle JE, Lambert BE, Moores SR. Radiation effects in the lung. Environ Health Perspect 1986;70:261-291.

2. Williams JP, Jackson IL, Shah JR, et al. Animal models and medical countermeasures development for radiation-induced lung damage: report from an NIAID Workshop. Radiat Res 2012;177:e0025-e0039.

3. Williams JP, Brown SL, Georges GE, et al. Animal models for medical countermeasures to radiation exposure. Radiat Res 2010;173: 557-578.

4. Roberts R, McCune SK. Animal studies in the development of medical countermeasures. Clin Pharmacol Ther 2008:83:918-920.

5. Hopewell JW, Rezvani M, Moustafa HF. The pig as a model for the study of radiation effects on the lung. Int J Radiat Biol 2000;76: 447-452.

6. Prato FS, Kurdyak R, Saibil EA, et al. The incidence of radiation pneumonitis as a result of single fraction upper half body irradiation. Cancer 1977;39:71-78.

7. Fryer CJ, Fitzpatrick PJ, Rider WD, et al. Radiation pneumonitis: experience following a large single dose of radiation. Int J Radiat Oncol Biol Phys 1978;4:931-936.

8. Van Dyk J, Keane TJ, Kan S, et al. Radiation pneumonitis following large single dose irradiation: a re-evaluation based on absolute dose to lung. Int J Radiat Oncol Biol Phys 1981;7:461-467.

9. Salazar OM, Rubin $\mathrm{P}$, Keller $\mathrm{B}$, et al. Systemic (half-body) radiation therapy: response and toxicity. Int J Radiat Oncol Biol Phys 1978;4: 937-950

10. Newton KA. Total thoracic irradiation combined with intravenous injection of autogenous marrow. Clin Radiol 1960;11:14-21.

11. Baeza MR, Barkley HT, Fernandez CH. Total-lung irradiation in the treatment of pulmonary metastases. Radiology 1975;116:151-154.

12. MacVittie TJ, Bennett A, Booth C, et al. The prolonged gastrointestinal syndrome in rhesus macaques: the relationship between gastrointestinal, hematopoietic, and delayed multi-organ sequelae following acute, potentially lethal, partial-body irradiation. Health Phys 2012;103:427-453.

13. Garofalo M, Bennett A, Farese $A M$, et al. The delayed pulmonary syndrome following acute high-dose irradiation: a rhesus macaque model. Health Phys 2014;106:56-72.

14. Jackson IL, Xu P-T, Nguyen G, et al. Characterization of the dose response relationship for lung injury following acute radiation exposure in three well-established murine strains: developing an interspecies bridge to link animal models with human lung. Health Phys 2014;106:48-55.

15. Sampath S, Schultheiss TE, Wong J. Dose response and factors related to interstitial pneumonitis after bone marrow transplant. Int J Radiat Oncol Biol Phys 2005;63:876-884.

16. Lockhart SP, Down JD, Steel GG. The effect of low dose-rate and cyclophosphamide on the radiation tolerance of the mouse lung. Int J Radiat Oncol Biol Phys 1986;12:1437-1440.

17. Down JD, Mauch $P$, Warhol M, et al. The effect of donor T lymphocytes and total- body irradiation on hemopoietic engraftment and pulmonary toxicity following experimental allogeneic bone marrow transplantation. Transplantation 1992;54:802-808.

18. Panoskaltsis-Mortari A, Taylor PA, Yaeger TM, et al. The critical early proinflammatory events associated with idiopathic pneumonia syndrome in irradiated murine allogeneic recipients are due to donor T cell infusion and potentiated by cyclophosphamide. J Clin Invest 1997:100:1015-1027.

19. Crawford SW, Hackman RC, Clark JG. Open lung biopsy diagnosis of diffuse pulmonary infiltrates after marrow transplantation. Chest 1988;94:949-953.
20. Keane TJ, Van Dyk J, Rider WD. Idiopathic interstitial pneumonia following bone marrow transplantation: the relationship with total body irradiation. Int J Radiat Oncol Biol Phys 1981;7: 1365-1370.

21. Depledge $\mathrm{MH}$, Barrett A, Powles RL. Lung function after bone marrow grafting. Int J Radiat Oncol Biol Phys 1983;9:145-151.

22. Weiner RS, Bortin MM, Gale RP, et al. Interstitial pneumonitis after bone marrow transplantation. Assessment of risk factors. Ann Intern Med 1986;104:168-175.

23. Baranov $A E$, Selidovkin $G D$, Butturini, et al. Hematopoietic recovery after 10-Gy acute total body radiation. Blood 1994;83:596-599.

24. Ishii T, Futami S, Nishida M, et al. Brief note and evaluation of acuteradiation syndrome and treatment of a Tokai-mura criticality accident patient. J Radiat Res (Tokyo) 2001;42 Suppl:S167-S182.

25. Changlin Y, Genyao Y. Multi-organ failure in a radiation accident: the Chinese experience of 1990. Br J Radiol Suppl 2005;27:47-54.

26. Rodrigues $G$, Lock $M$, D'Souza $D$, et al. Prediction of radiation pneumonitis by dose-volume histogram parameters in lung cancera systematic review. Radiother Oncol 2004;71:127-138.

27. Willner J, Jost A, Baier $K$, et al. A little to a lot or a lot to a little? An analysis of pneumonitis risk from dose-volume histogram parameters of the lung in patients with lung cancer treated with 3-D conformal radiotherapy. Strahlenther Onkol 2003;179:548-556.

28. Marks LB, Bentzen SM, Deasy JO, et al. Radiation dose-volume effects in the lung. Int J Radiat Oncol Biol Phys 2010;76:S70-S76.

29. Gross NJ. Pulmonary effects of radiation therapy. Ann Intern Med 1977;86:81-92.

30. Rosen II, Fischer TA, Antolak JA, et al. Correlation between lung fibrosis and radiation therapy dose after concurrent radiation therapy and chemotherapy for limited small cell lung cancer. Radiology 2001;221:614-622.

31. Vågane $\mathrm{R}$, Bruland ØS, Fosså SD, et al. Radiological and functional assessment of radiation- induced pulmonary damage following breast irradiation. Acta Oncol Stockh Swed 2008:47:248-254.

32. Allen $A M$, Czerminska M, Jänne PA, et al. Fatal pneumonitis associated with intensity-modulated radiation therapy for mesothelioma. Int J Radiat Oncol Biol Phys 2006:65:640-645.

33. Choi YW, Munden RF, Erasmus JJ, et al. Effects of radiation therapy on the lung: radiologic appearances and differential diagnosis. Radiographics 2004;24:985-997; discussion 998.

34. Scheenstra AEH, Rossi MMG, Belderbos JSA, et al. Local dose-effect relations for lung perfusion post stereotactic body radiotherapy. Radiother Oncol 2013;107:398-402.

35. Kocak Z, Borst GR, Zeng J, et al. Prospective assessment of dosimetric/ physiologic-based models for predicting radiation pneumonitis. Int Radiat Oncol Biol Phys 2007;67:178-186.

36. Seppenwoolde $Y$, De Jaeger K, Boersma L, et al. Regional differences in lung radiosensitivity after radiotherapy for non-small-cell lung cancer. Int J Radiat Oncol Biol Phys 2004;60:748-758.

37. Boersma LJ, Damen EM, de Boer RW, et al. Dose-effect relations for local functional and structural changes of the lung after irradiation for malignant lymphoma. Radiother Oncol 1994;32:201-209.

38. Fleckenstein K, Zgonjanin L, Chen L, et al. Temporal onset of hypoxia and oxidative stress after pulmonary irradiation. Int J Radiat Oncol Biol Phys 2007:68:196-204.

39. Hughes JM. Lung gas tensions and active regulation of ventilation/ perfusion ratios in health and disease. Br J Dis Chest 1975;69:153-170.

40. West J. Pulmonary Pathophysiology-The Essentials, 3rd edn. Williams \& Wilkins: London, 1987.

41. McDonald S, Rubin P, Phillips $T L$, et al. Injury to the lung from cancer therapy: clinical syndromes, measurable endpoints, and potential scoring systems. Int J Radiat Oncol Biol Phys 1995;31: 1187-1203.

42. Pagani JJ, Libshitz HI. CT manifestations of radiation-induced change in chest tissue. J Comput Assist Tomogr 1982;6:243-248.

43. Deeley TJ. The effects of radiation on the lungs in the treatment of carcinoma of the bronchus. Clin Radiol 1960;11:33-39.

44. Theuws JC, Seppenwoolde $\mathrm{Y}, \mathrm{Kwa} \mathrm{SL}$, et al. Changes in local pulmonary injury up to 48 months after irradiation for lymphoma and breast cancer. Int J Radiat Oncol Biol Phys 2000:47:1201-1208.

45. Nicholas D, Down JD. The assessment of early and late radiation injury to the mouse lung using X-ray computerised tomography. Radiother Oncol 1985;4:253-263. 
46. Granton PV, Dubois L, van Elmpt W, et al. A longitudinal evaluation of partial lung irradiation in mice by using a dedicated image-guided small animal irradiator. Int J Radiat Oncol Biol Phys 2014;90:696-704.

47. Down JD, Nicholas D, Steel GG. Lung damage after hemithoracic irradiation: dependence on mouse strain. Radiother Oncol 1986;6: 43-50.

48. Law MP, Hornsey S, Field SB. Collagen content of lungs of mice after x-ray irradiation. Radiat Res 1976;65:60-70.

49. Law MP. Vascular permeability and late radiation fibrosis in mouse lung. Radiat Res 1985;103:60-76.

50. Collins JF, Johanson WG, McCullough B, et al. Effects of compensatory lung growth in irradiation-induced regional pulmonary fibrosis in the baboon. Am Rev Respir Dis 1978;117:1079-1089.

51. Rube CE, Uthe D, Schmid KW, et al. Dose-dependent induction of transforming growth factor beta (TGF-beta) in the lung tissue of fibrosis-prone mice after thoracic irradiation. Int J Radiat Oncol Biol Phys 2000;47:1033-1042.

52. Stone HB, Moulder JE, Coleman CN, et al. Models for evaluating agents intended for the prophylaxis, mitigation and treatment of radiation injuries. Report of an NCI Workshop, December 3-4, 2003. Radiat Res 2004;162:711-728.

53. Rodemann HP, Blaese MA. Responses of normal cells to ionizing radiation. Semin Radiat Oncol 2007;17:81-88.

54. Bentzen SM. Preventing or reducing late side effects of radiation therapy: radiobiology meets molecular pathology. Nat Rev Cancer 2006;6:702-713.

55. Yarnold J, Brotons M-CV. Pathogenetic mechanisms in radiation fibrosis. Radiother Oncol 2010;97:149-161.

56. Hallahan DE, Virudachalam S. Intercellular adhesion molecule 1 knockout abrogates radiation induced pulmonary inflammation. Proc Natl Acad Sci USA 1997;94:6432-6437.

57. Down JD, Steel GG. The expression of early and late damage after thoracic irradiation: a comparison between CBA and C57B1 mice. Radiat Res 1983;96:603-610.

58. Sharplin J, Franko AJ. A quantitative histological study of straindependent differences in the effects of irradiation on mouse lung during the early phase. Radiat Res 1989;119:1-14.

59. Rubin $\mathrm{P}$, Johnston CJ, Williams JP, et al. A perpetual cascade of cytokines postirradiation leads to pulmonary fibrosis. Int J Radiat Oncol Biol Phys 1995;33:99-109.

60. Hill RP. Radiation effects on the respiratory system. Br J Radiol Suppl 2005;27:75-81.

61. Jackson IL, Vujaskovic Z, Down JD. Revisiting strain-related differences in radiation sensitivity of the mouse lung: recognizing and avoiding the confounding effects of pleural effusions. Radiat Res 2010;173:10-20.

62. Jackson IL, Vujaskovic Z, Down JD. A further comparison of pathologies after thoracic irradiation among different mouse strains: finding the best preclinical model for evaluating therapies directed against radiation-induced lung damage. Radiat Res 2011;175:510-518.

63. Schaue D, Kachikwu EL, McBride WH. Cytokines in radiobiological responses: a review. Radiat Res 2012;178:505-523.

64. Paun A, Kunwar A, Haston CK. Acute adaptive immune response correlates with late radiation- induced pulmonary fibrosis in mice. Radiat Oncol 2015;10:45.

65. Wang L, Zhang J, Wang B, et al. Blocking HMGB1 signal pathway protects early radiation- induced lung injury. Int J Clin Exp Pathol 2015;8:4815-4822.

66. Herzog EL, Van Arnam J, Hu B, et al. Threshold of lung injury required for the appearance of marrow-derived lung epithelia. Stem Cells 2006;24:1986-1992.

67. Mathew B, Jacobson JR, Siegler JH, et al. Role of migratory inhibition factor in age-related susceptibility to radiation lung injury via NF-E2related factor-2 and antioxidant regulation. Am J Respir Cell Mol Biol 2013;49:269-278.

68. Hong J-H, Jung S-M, Tsao TCY, et al. Bronchoalveolar lavage and interstitial cells have different roles in radiation-induced lung injury. Int J Radiat Biol 2003;79:159-167.

69. Hong $\mathrm{JH}$, Chiang $\mathrm{CS}$, Tsao $\mathrm{CY}$, et al. Can short-term administration of dexamethasone abrogate radiation-induced acute cytokine gene response in lung and modify subsequent molecular responses? Int J Radiat Oncol Biol Phys 2001;51:296-303.
70. Rubin P, Siemann DW, Shapiro DL, et al. Surfactant release as an early measure of radiation pneumonitis. Int J Radiat Oncol Biol Phys 1983;9: 1669-1673.

71. Down JD, Coultas PG, Field SB. Is surfactant release a reliable predictor of radiation pneumonitis? Int J Radiat Oncol Biol Phys 1988;14:211-212.

72. Stewart F, Van der Kogel A. Proliferative and cellular organization of normal tissues. In: Steel GG (ed). Basic Clinical Radiobiology, 2nd edn. Arlond: London, 1997, p 24.

73. Coggle JE. Proliferation of type II pneumonocytes after X-irradiation. Int J Radiat Biol Relat Stud Phys Chem Med 1987;51:393-399.

74. Coultas PG, Ahier RG, Field SB. Effects of neutron and X irradiation on cell proliferation in mouse lung. Radiat Res 1981;85:516-528.

75. Meyer KR, Ullrich RL. Effects of $X$ rays and fission neutrons on an induced proliferative response in lung type 2 epithelial cells. Radiat Res 1981;85:380-389.

76. Adamson IY, Bowden DH, Cote MG, et al. Lung injury induced by butylated hydroxytoluene: cytodynamic and biochemical studies in mice. Lab Invest 1977;36:26-32.

77. Steel GG. The case against apoptosis. Acta Oncol 2001;40:968-975.

78. Collis $\mathrm{CH}$, Down JD, Pearson $\mathrm{AE}$, et al. Bleomycin and radiationinduced lung damage in mice. Br J Radiol 1983;56:21-26.

79. Collis $\mathrm{CH}$, Steel GG. Lung damage in mice from cyclophosphamide and thoracic irradiation: the effect of timing. Int J Radiat Oncol Biol Phys 1983;9:685-689.

80. Ullrich RL, Meyer KR. The influence of butylated hydroxytolueneinduced cell proliferation on mouse lung damage after $x$ rays or fission neutrons. Radiat Res 1982;89:428-432.

81. Manning CM, Johnston CJ, Hernady $E$, et al. Exacerbation of lung radiation injury by viral infection: the role of Clara cells and Clara cell secretory protein. Radiat Res 2013;179:617-629.

82. Paun A, Haston CK. Genomic and genome-wide association of susceptibility to radiation-induced fibrotic lung disease in mice. Radiother Oncol 2012;105:350-357.

83. Stavrev P, Stavreva N, Sharplin J, et al. Critical volume model analysis of lung complication data from different strains of mice. Int J Radiat Biol 2005;81:77-88.

84. Blank LE, Haveman J, van Zandwijk N. The radioprotective effect of $\mathrm{N}$-acetylcysteine in thorax irradiation of mice. Radiother Oncol 1987;10:67-69.

85. Travis EL, Rachakonda G, Zhou X, et al. NRF2 deficiency reduces life span of mice administered thoracic irradiation. Free Radic Biol Med 2011;51:1175-1183.

86. Down JD, Yanch JC. Identifying the high radiosensitivity of the lungs of C57L mice in a model of total-body irradiation and bone marrow transplantation. Radiat Res 2010;174:258-263.

87. Jackson $\mathrm{IL}, \mathrm{Xu} \mathrm{P}$, Hadley $\mathrm{C}$, et al. A preclinical rodent model of radiation-induced lung injury for medical countermeasure screening in accordance with the FDA animal rule. Health Phys 2012;103:463-473.

88. Down JD, Easton DF, Steel GG. Repair in the mouse lung during low dose-rate irradiation. Radiother Oncol 1986;6:29-42.

89. Down JD, Tarbell NJ, Warhol $M$, et al. Dose-limiting complications from upper half body irradiation in $\mathrm{C} 3 \mathrm{H}$ mice. Int J Radiat Oncol Biol Phys 1988;14:483-489.

90. Sharplin J, Franko AJ. A quantitative histological study of straindependent differences in the effects of irradiation on mouse lung during the intermediate and late phases. Radiat Res 1989;119:15-31.

91. Dileto $\mathrm{CL}$, Travis EL. Fibroblast radiosensitivity in vitro and lung fibrosis in vivo: comparison between a fibrosis-prone and fibrosisresistant mouse strain. Radiat Res 1996;146:61-67.

92. Haston CK, Travis EL. Murine susceptibility to radiation-induced pulmonary fibrosis is influenced by a genetic factor implicated in susceptibility to bleomycin-induced pulmonary fibrosis. Cancer Res 1997;57:5286-5291.

93. Haston CK, Begin M, Dorion G, et al. Distinct loci influence radiationinduced alveolitis from fibrosing alveolitis in the mouse. Cancer Res 2007;67:10796-10803.

94. Down JD, Laurent GJ, McAnulty RJ, et al. Oxygen-dependent protection of radiation lung damage in mice by WR 2721. Int J Radiat Biol 1984;46:597-607.

95. Travis EL, Meistrich ML, Finch-Neimeyer MV, et al. Late functional and biochemical changes in mouse lung after irradiation: differential effects of WR-2721. Radiat Res 1985;103:219-231. 
96. Puthawala K, Hadjiangelis N, Jacoby SC, et al. Inhibition of integrin alpha(v)beta6, an activator of latent transforming growth factor-beta, prevents radiation-induced lung fibrosis. Am J Respir Crit Care Med 2008;177:82-90.

97. Hallahan DE, Geng L, Shyr Y. Effects of intercellular adhesion molecule 1 (ICAM-1) null mutation on radiation-induced pulmonary fibrosis and respiratory insufficiency in mice. J Natl Cancer Inst 2002;94: 733-741.

98. Machtay M, Scherpereel A, Santiago J, et al. Systemic polyethylene glycol-modified (PEGylated) superoxide dismutase and catalase mixture attenuates radiation pulmonary fibrosis in the $\mathrm{C} 57 \mathrm{BL} /$ 6 mouse. Radiother Oncol 2006;81:196-205.

99. Fox J, Haston CK. CXC receptor 1 and 2 and neutrophil elastase inhibitors alter radiation-induced lung disease in the mouse. Int J Radiat Oncol Biol Phys 2013;85:215-222.

100. Travis EL, Down JD, Holmes SJ, et al. Radiation pneumonitis and fibrosis in mouse lung assayed by respiratory frequency and histology. Radiat Res 1980;84:133-143.

101. Travis EL, Down JD. Repair in mouse lung after split doses of $X$ rays. Radiat Res 1981;87:166-174.

102. Travis EL, Parkins CS, Holmes SJ, et al. WR-2721 protection of pneumonitis and fibrosis in mouse lung after single doses of $\mathrm{x}$ rays. Int J Radiat Oncol Biol Phys 1984;10:243-251.

103. Barnes DW, Bungay GT, Mole RH. Delayed mortality after mid-lethal exposures to whole body irradiation and its modification by treatment with syngeneic lymph-node or bone-marrow cells. Int J Radiat Biol 1966;11:409-427.

104. Hollander C, Van Bekkum D. Pathology of the late syndrome in mice lethally irradiated and treated with isologous bone-marrow transplantation. Int J Radiat Biol 1969;16:70

105. Covelli V, Metalli P, Briganti G, et al. Late somatic effects in syngeneic radiation chimaeras. II. Mortality and rate of specific diseases. Int J Radiat Biol 1974:26:1-15.

106. Gross NJ. Experimental radiation pneumonitis: changes in physiology of the alveolar surface. J Lab Clin Med 1978;92:991-1001.

107. Down JD, Tarbell NJ. Pitfalls in the assessment of late lung damage in irradiated mice: complications related to pleural effusion. Int J Radiat Biol 1989;55:473-478.

108. Down JD. The nature and relevance of late lung pathology following localised irradiation of the thorax in mice and rats. Br J Cancer Suppl 1986;7:330-332.

109. Franko AJ, Sharplin J. Development of fibrosis after lung irradiation in relation to inflammation and lung function in a mouse strain prone to fibrosis. Radiat Res 1994;140:347-355.

110. Franko AJ, Sharplin J, Ghahary, et al. Immunohistochemical localization of transforming growth factor beta and tumor necrosis factor alpha in the lungs of fibrosis-prone and 'non-fibrosing' mice during the latent period and early phase after irradiation. Radiat Res 1997;147:245-256

111. Haston CK, Zhou X, Gumbiner-Russo $L$, et al. Universal and radiationspecific loci influence murine susceptibility to radiation-induced pulmonary fibrosis. Cancer Res 2002;62:3782-3788.

112. Liao ZX, Travis EL, Tucker SL. Damage and morbidity from pneumonitis after irradiation of partial volumes of mouse lung. Int J Radiat Oncol Biol Phys 1995;32:1359-1370.

113. van der Veen SJ, Ghobadi G, de Boer RA, et al. ACE inhibition attenuates radiation-induced cardiopulmonary damage. Radiother Oncol 2015;114:96-103.

114. Medhora M, Gao F, Glisch C, et al. Whole-thorax irradiation induces hypoxic respiratory failure, pleural effusions and cardiac remodeling. J Radiat Res 2015;56:248-260.

115. Shirai K, Tamaki Y, Kitamoto Y, et al. Dose-volume histogram parameters and clinical factors associated with pleural effusion after chemoradiotherapy in esophageal cancer patients. Int J Radiat Oncol Biol Phys 2011;80:1002-1007.

116. Halpenny D, Ridge CA, Hayes S, et al. Computed tomographic features predictive of local recurrence in patients with early stage lung cancer treated with stereotactic body radiation therapy. Clin Imaging 2015;39:254-258.
117. Rodríguez-García JL, Fraile G, Moreno MA, et al. Recurrent massive pleural effusion as a late complication of radiotherapy in Hodgkin's disease. Chest 1991;100:1165-1166.

118. Morrone N, Gama e Silva Volpe VL, Dourado AM, et al. Bilateral pleural effusion due to mediastinal fibrosis induced by radiotherapy. Chest 1993;104:1276-1278.

119. Van Renterghem DM, Pauwels RA. Chylothorax and pleural effusion as late complications of thoracic irradiation. Chest 1995;108:886-887.

120. Cui Y, Wilder J, Rietz C, et al. Radiation-induced impairment in lung lymphatic vasculature. Lymphat Res Biol 2014;12:238-250.

121. Thomas DM, Fox J, Haston CK. Imatinib therapy reduces radiationinduced pulmonary mast cell influx and delays lung disease in the mouse. Int J Radiat Biol 2010;86:436-444.

122. Fox J, Gordon JR, Haston CK. Combined CXCR1/CXCR2 antagonism decreases radiation-induced alveolitis in the mouse. Radiat Res 2011;175:657-664.

123. Gross NJ, Narine KR, Wade R. Protective effect of corticosteroids on radiation pneumonitis in mice. Radiat Res 1988;113:112-119.

124. Gross NJ, Holloway NO, Narine KR. Effects of some nonsteroidal antiinflammatory agents on experimental radiation pneumonitis. Radiat Res 1991;127:317-324.

125. Ward WF, Shih-Hoellwarth A, Pearlman HG, et al. Whole-thorax radiation lethality in penicillamine-treated mice. Radiat Res 1982;90:321-329.

126. Hunter NR, Valdecanas D, Liao Z, et al. Mitigation and treatment of radiation-induced thoracic injury with a cyclooxygenase-2 inhibitor, celecoxib. Int J Radiat Oncol 2013;85:472-476.

127. Landes RD, Lensing SY, Kodell RL, et al. Practical advice on calculating confidence intervals for radioprotection effects and reducing animal numbers in radiation countermeasure experiments. Radiat Res 2013;180:567-574.

128. Parkins C, Fowler JF, Denekamp J. Lung radioprotection by WR-2721 at low X-ray doses per fraction. Eur J Cancer Clin Oncol 1984;20:1445-1450.

129. Travis EL. Genetic susceptibility to late normal tissue injury. Semin Radiat Oncol 2007;17:149-155.

130. Baker R, Han G, Sarangkasiri S, et al. Clinical and dosimetric predictors of radiation pneumonitis in a large series of patients treated with stereotactic body radiation therapy to the lung. Int J Radiat Oncol Biol Phys 2013;85:190-195.

131. Takeda A, Ohashi T, Kunieda $E$, et al. Comparison of clinical, tumourrelated and dosimetric factors in grade $0-1$, grade 2 and grade 3 radiation pneumonitis after stereotactic body radiotherapy for lung tumours. Br J Radiol 2012;85:636-642.

132. Robnett TJ, Machtay $M$, Vines $E F$, et al. Factors predicting severe radiation pneumonitis in patients receiving definitive chemoradiation for lung cancer. Int J Radiat Oncol Biol Phys 2000;48:89-94.

133. Dang J, Li G, Lu X, et al. Analysis of related factors associated with radiation pneumonitis in patients with locally advanced non-smallcell lung cancer treated with three- dimensional conformal radiotherapy. J Cancer Res Clin Oncol 2010;136:1169-1178.

134. Claude L, Pérol D, Ginestet C, et al. A prospective study on radiation pneumonitis following conformal radiation therapy in non-small-cell lung cancer: clinical and dosimetric factors analysis. Radiother Oncol 2004;71:175-181.

135. National Research Council (US). Committee Guide for the Care and Use of Laboratory Animals, [Internet], 8th edn. National Academies Press: Washington (DC), 2011, [cited 23 October 2015]. Available from https://grants.nih.gov/grants/olaw/Guide-for-the-Care-and-use-oflaboratory-animals.pdf.

136. Okayasu R, Suetomi $\mathrm{K}, \mathrm{Yu} \mathrm{Y}$, et al. A deficiency in DNA repair and DNA- PKcs expression in the radiosensitive BALB/c mouse. Cancer Res 2000;60:4342-4345.

137. Almeida C, Nagarajan D, Tian J, et al. The role of alveolar epithelium in radiation-induced lung injury. PLoS One 2013;8:e53628.

138. Wong J, Armour E, Kazanzides $\mathrm{P}$, et al. High-resolution, small animal radiation research platform with $\mathrm{x}$-ray tomographic guidance capabilities. Int J Radiat Oncol Biol Phys 2008;71:1591-1599.

139. Clarkson R, Lindsay PE, Ansell $S$, et al. Characterization of image quality and image-guidance performance of a preclinical microirradiator. Med Phys 2011;38:845-856. 